\title{
Reassessing the Impact of Financial Services on Urban Manufacturing Firms: An Impact Evaluation Method in Ethiopia
}

\author{
Zerayehu Sime Eshete ${ }^{1} \&$ Bisrat Legesse Kidane ${ }^{2}$ \\ ${ }^{1}$ Department of Economics, Addis Ababa University, Addis Ababa, Ethiopia \\ ${ }^{2}$ Yom Institute of Economic Development, Addis Ababa, Ethiopia \\ Correspondence: Zerayehu Sime Eshete, Department of Economics, Addis Ababa University, Ethiopia. Tel: 251- \\ 9-3447-2215. E-mail: zerayehu.sime@aau.edu.et
}

\author{
Received: May 11, 2020 \\ Accepted: May 20, 2020 \\ Online Published: July 29, 2020 \\ doi:10.5539/jsd.v13n4p129 \\ URL: https://doi.org/10.5539/jsd.v13n4p129
}

\begin{abstract}
The stock of financial literature reveals emerging and conflicting stands on the effect of finance on the performance of the economy. The previous thoughts considered finance into account as an important driving force to growth through its role in intermediation, reduction of transaction costs and risk, and efficient uses of resources. Nevertheless, the newly emerging thoughts focus on the vanishing effect of finance due to its stiff competition over resources with the rest of the economy. The dialogues also reflected in the process of industrialization and promoting the manufacturing sector. Therefore, the general objective of this study is to reexamine the impact of financial services on the performance of manufacturing firms in Ethiopia with a special focus on firms in Addis Ababa. The study used propensity score matching method. The result shows that those who access finance has increased their operating margin profit by 2.6 on average in comparison with the non-treated groups. The treated groups have 0.42 greater net return on a net asset than non-treated groups on average. Therefore, the study suggests that financial institutions should increase their involvement to expand the accessibility of financial products to manufacturing firms that are the expected engines of sustainable growth and economic transformation.
\end{abstract}

Keywords: finance, manufacturing, propensity score matching, treated group, untreated group

\section{Introduction}

It is believed that finance plays a pivotal role in activating the performance of an economy and filling the resource gaps in business activities. It also places a strong contribution to speeding up the process of economic transformation which is highly required to cure the problem of developing countries. Ethiopia in this regard is a predominantly agrarian economy with a limited share of the manufacturing sector in GDP, around 5 percent over the last decades. The manufacturing sector, in particular, has been constrained by a lack of finance, crippling down the role of industry in the economy. Rather, the majority of bank credit has been allocated to the service sector to run a small business and hotel activities, less attention to the manufacturing sector over the last decades. For instance, the public banks constitute 77 percent of total assets of the banking sector, and around 80 percent of their total outstanding loans are used to finance public investments, adversely affecting the privately owned manufacturing industries (MoEFC, 2016).

The Ethiopian government has therefore embarked on an ambitious plan of making the country a hub of light manufacturing in Africa. Currently, the country constructs 13 industrial parks to attract investment in the agroprocessing industry and 15 's are contributing to the creation of two million manufacturing jobs for five years (EBR, 2017). The manufacturing sector that constitutes around 70 percent of the industry sector involves a range of industrial and processing of items as well as the creation of new products or value addition (CSA, 2016). Following this, the investors put great attention to the sector to reap the expected remarkable profitability of the firms.

According to the primary survey, this sub-sector relies highly on domestic banks to meet its financial resource demand. The survey result indicates that 55 percent of the manufacturing firms use domestic banks as the main source of finance. This is followed by saving (16\%), foreign investor/partner (9\%), domestic capital market (4\%), and other unmentioned sources $(16 \%)$. However, a lack of finance adversely affects profit growth and is a major bottleneck for investment. To evident this, bank loan given to the sector is very small, the collateral required is huge, direct and indirect service payments are high, risk evaluation capacity is inadequate, access to foreign 
exchange is problematic and there is a problem of access to finance for manufacturing enterprises.

The main purpose of this study is to evaluate the impact of access to finance on the performance of manufacturing firms using propensity score matching method in consideration of the livelihood of treated firms (who got access to finance) in comparison with a counterfactual group (who does not have access to finance). The result of this study also justified that increasing a financial accession to the manufacturing sector has a positive effect, not vanishing effect as some recent literature stated, and helps the government to draw great attention to the sector instead of highly engaged in allocating scarce financial resources to public enterprises for securing the economic transformation process in Ethiopia.

The role of the financial sector has been well recognized in the development literature. The seminal work of Patrick (1966) concludes finance is an engine for economic growth and points out two possible relations between financial development and economic growth: 'demand-following phenomenon' and supply-leading phenomenon. This latter view dubs the 'financial-led growth hypothesis' that has been popular in developing countries to promote development (Habibullah and Eng, 2006; King and Levine, 1998). However, Lucas (1988) argues that economists "badly overstress" the significance of financial consideration. Regarding the linkage, Greenwood and Jovanovic (1990) show how well financial development and economic growth interacted with each other in the sense of income inequality. Beck et.al., (2004) also examined whether the level of financial intermediation influences the growth rate of Gini coefficient of income inequality and revealed legal implications for financial development via the political channel and adaptability channel through which legal origin affects credit market (La Porta et.al., 1998).

From the macroeconomic framework, the Structuralist school also recommends an expansion in the structure of the financial system and an increase in the array of financial instruments and institutions (Goldsmith, 1969: Patrick, 1966). And, neoliberals, on the other hand, advocate the liberalization of the financial system (McKinnon, 1973: Shaw, 1973), which focuses on price stabilization and static allocative efficiency in the reassertion of orthodox economics (Saad, 2006).

In this regards, the relationship between finance and growth fundamentally based on the role of manufacturing firm productivity, which is possibly affected by the quality of infrastructure, the experience and education of the labor force, the cost and access to financing, and different dimensions of the government-business relationship (Plane et.al, 2011). Multiple empirical kinds of literature show that the manufacturing firm's performance is directly related to access to credit. In the developing world, the size of firms is directly related to access to finance.

An empirical study made in six Latin American countries (2002) suggested that access to credit and its costs influenced by the relation between firms and financiers rather than their favorable cash flow \& asset building. The results also show that firms with foreign stakeholders and associated with business groups have better access to finance. A post \& after financial liberalization valuation made on the impact of financial limitations the result shows that financial liberalization reduces financial constraints for firms (Arturo, 2002).

The study over industrial firms of six African countries in 2003 found out that only $25 \%$ of manufacturing firms that required credit got a formal loan. The results suggest that large firms have better access to credit than smaller \& micro industrial firms and further the smaller firms have to be more profitable to get credit. Also, there is a positive relationship between the remaining loan and accessing credit. (Arne, 2003)

The specific study made Small-scale enterprises (SME's) access to credit, especially in Westland's area of Kenya finds that 58 percent generally agreed that establishing a relationship with the loaning institutions would ease the load of borrowing. The lending organizations were found to look at the financial performance of the candidate before extending credit. But due to lack of a well detailed financial reporting, such records would not be viable evidence for lenders to extend credit. Also, 84 percent generally agreed that business skills acquired before would impact access to funding. (Gabriel, 2011). A study made on access to finance on 78 SME Industrial firms in Ghana showed that access to credit growth in total current investment, start-up capital, and annual turnover, which in turn have a significant positive effect on the growth of SMEs in the industrial sector and employment. (Anthony, 2012).

Both theoretical and empirical literature indicates that there are emerging and conflicting issues on the effect of finance on the performance of the economy. In the previous thought, it is believed that finance is important to growth through creating intermediation between borrowers and lenders, reducing transaction costs, reducing risk, promoting efficient uses of resources, and lubricating the system of the economy (Goldsmith, 1969; McKinnon,1973 and Shaw, 1973). However, recently, a newly emerging issue comes into existence and declares the vanishing effect of finance based on the justification that underlines the financial industry competes for physical and human resources with the rest of the economy. Such a negative effect on growth is primarily motivated by advanced economies, not by developing countries. This implies that there is a belief that there is a nonlinear 
relationship between finance and growth depending on the transmission mechanism of finance and the level of development, leads to an inverted $U$ shape relationship and a weakened influence over time (Rousseau and Wachtel,2011). The effect could also depend on the trend of marginal returns and there must a threshold where accession to finance can be no longer promote growth (De la Torre et al., 2011 and Arcand et al., 2015), Therefore, this study reexamines the traditional view in the Ethiopian manufacturing industry.

\section{Materials and Methods}

\subsection{The Study Area}

Ethiopia manufacturing sector is at its infant stage with few players supplying to the market. There is 3,150 large and medium scale Manufacturing. As it shows the distribution of large and medium scale manufacturing industries both public and private by regional state and industrial groups. The total number of small, medium, and large manufacturing industries in Addis Ababa accounted for 2789(58.0 percent), 1583 (33 percent), 414(9 percent) in 2020. The total number of large and medium scale manufacturing industries reported in the 2015 survey was 3,150 . The distribution of manufacturing industries has been more dominated by small scale manufacturing industry in Addis Ababa. More than 35 percent of the manufacturing industries were located in Addis Ababa followed by Oromia with almost 32 percent and Amhara with almost 11 percent of the industries. The industrial groups of more than 29 percent are manufacturing of food and beverages, 19 percent manufacturing of other non-metallic minerals products, and 12 percent Manufacturing of furniture and others in the 2015 survey.

\subsection{Data Required for the Study}

Both quantitative and qualitative types of data were collected to achieve the research objective and triangulation also conducted. The quantitative data were collected through well design close-ended questionnaires from the selected firms that are involved in financial accession and those not yet for the comparison.

Primary data source, including, beneficiary and non-beneficiary firms using a cloth-ending questionnaire, but some of the questionnaire was open-ended to firms on the selected respondent. The tools for the collection of both quantitative and qualitative data decoded by understanding the requirements and research questions. Thus, the research requires data collection tools that are suitable to generate data to investigate, research questions in line with the objective of the study. Therefore, Questionnaires' data collection tools were made to find answers to the posed research questions satisfactorily.

In the estimation of the propensity score, the effect of covariant on the PS is not interested because the study aims to assess the impact of access to finance on manufacturing firms in Profitability. However, in the first step of PS estimation to choose the covariant (Heckman., 1997).

Table 1. Variable choice and definition

\begin{tabular}{|c|c|c|}
\hline Variable & Type and definition & measurement \\
\hline \multicolumn{3}{|l|}{ Dependent variable } \\
\hline OPRMA & Continuous, Operating margin Profit & $\begin{array}{l}\text { If the result is }>1 \text { the company is in Profit and } \\
\text { if, }<1 \text { the company is in loss }\end{array}$ \\
\hline RANERENEASS & $\begin{array}{l}\text { Continuous, Rate of the net return on net } \\
\text { asset }\end{array}$ & $\begin{array}{l}\text { If the result is }>1 \text { the company is in Profit and } \\
\text { if, }<1 \text { the company is in loss }\end{array}$ \\
\hline \multicolumn{3}{|l|}{ Covariates } \\
\hline Exp & Continuous, Age of the firm (Experience) & In Year \\
\hline CAP & $\begin{array}{l}\text { Continuous, Total amount of paid-up } \\
\text { capital of the firm }\end{array}$ & In Ethiopian currency, birr \\
\hline Emp. No. & Continuous, Number of Employees & In number \\
\hline TOEXP & Continuous, Expense of the firms & In Ethiopian currency, birr \\
\hline NEASS & Continuous, Asset of the firms & In Ethiopian currency, birr \\
\hline \multicolumn{3}{|l|}{ Controlled variable } \\
\hline \multirow{2}{*}{ Finance } & \multirow{2}{*}{ Dummy variable } & If they took credit-1 \\
\hline & & If they couldn't take credit -0 \\
\hline
\end{tabular}

SOURCE: OWN DEFINITION 


\subsection{Study Population and Sampling Technique}

The base for drawing the sample was the total number of manufacturing which accounts for 3,150 in the 2015 survey, of which 35 percent $(1,102)$ of them are located in Addis Ababa. By proportion, the study took 10 percent of them as sample size and collected data of 108 firms in consideration of accessing financial service. The purposive sampling technique was also employed in the study.

\subsection{Propensity Score Matching Method}

More than $35 \%$ of the manufacturing industries were located in Addis Ababa. The base for drawing the sample was the total number of manufacturing was convenient sampling so that the paper considers a sample size of 108 firms through a questionnaire. To estimate the impact of the intervention on the treated groups, the propensity score matching analysis was also used. The sample size for this study was taken from both the beneficiaries (treatment) and nonbeneficiary (control group) manufacturing firms.

Depending on the position of the firms in the treatment, participants, or non-participant to estimating the individual treatment effect is not possible, thus, shift to estimate the average treatment effect (ATE). Which is simply different from the expected outcome of after participation and non-participation. According to (Heckman, 1997) ATE $=\mathrm{E}$ $(\Delta Y)=\mathrm{E}\left(Y_{i}\right)-\mathrm{E}\left(Y_{0}\right)$ this estimate might not be significant to policymaker the reason of this, it includes the effect for whom the involvement was never intended. Therefore, the most important valuation parametric is called the average treatment effect on the treated $(\mathrm{ATT})=\mathrm{E}(\mathrm{T} / \mathrm{D}=1)=\mathrm{E}\left(Y_{i} / \mathrm{D}=1\right)-\mathrm{E}\left(Y_{0} / \mathrm{D}=1\right)$. This measure the effect on those for whom the intervention is intended. Non-experimental study one has to introduce some identifying assumptions to solve the selection problem.

The propensity score is the probability of a case to be counted in the treatment group based on observed characteristics and it used to balance the control variable between TG and C (Rosenbaum and Rubin, 1983). It constructs a statistical comparison group then based on a model of the probability of participating in the treatment using observation characteristics. The degree of similarities between different units is measured based on the probability of being exposed to the intervention given a set of observable characteristics not affected by the program. Once the two groups are matched based on observation, the average treatment effect of the intervention is as the mean effect of the treatment can then be calculated as the average difference in outcomes between the treated and non-treated units after matching across treated and control groups.

This propensity value is estimated based on a statistical model, e.g., logit or probit model, and thereby estimating the average treatment effect of the outcome difference between the two groups using nearest-neighbor, caliper, stratification, and kernel matching (Khandker et al., 2009). It is useful when there are many potential characteristics to match between program participants and non-participants. It is more robust compared to others (Pufahl and Weiss, 2009). A second assumption is the common support or overlap condition: $0<\mathrm{P}(\mathrm{Ti}=1 \mid \mathrm{Xi})<1$. This condition ensures that treatment observations have comparison observations "nearby" in the propensity score distribution.

\section{Results and Discussion}

In the application of the econometric model (Propensity Score Matching) estimation, an inferential statistic such as t-test is conducted to compare the treatment and control group for the different types of variables. The propensity score matching methods are employed to evaluate if the firms that took credits have a significant impact on the profitability of manufacturing firms in comparison with untreated groups.

\subsection{Two-Sample t-Test on Rate of Net Return on Net Asset}

The two-sample t-test to check the credit access program is significantly related to the outcome variable (the rate of the net return on the net asset) of the manufacturing firms. The mean value of this rate of return to the treated firms is equal to 0.8 and that of the control firms is 0.4 , implying that the net return on net asset for the control group is less than almost by half compared to the treated group. The two-sample t-test shows that the treated and the control group firms with their rate of the gross net asset are -2.7623 and this difference is statistically significant at the 1 percent level. 
Table 2. Two-sample T-test on outcome variables before matching

\begin{tabular}{lccccc}
\hline \multicolumn{1}{c}{ Group } & Obs. & Mean & SE & SD & t-Value \\
\hline Controlled & 66 & 0.4288182 & 0.0366988 & 0.2981424 & \\
Treated & 42 & 0.8111429 & 0.1640439 & 1.063126 & \\
Combined & 108 & 0.5775 & 0.0695317 & 0.7225941 & \\
\hline diff & & 0.3823247 & 0.1384057 & & $\mathrm{t}=-2.7623$ \\
\hline
\end{tabular}

Note: Obs.=Observation, $\mathrm{SE}=$ Standard Error; $\mathrm{SD}=$ Standard Division

\subsection{Two-Sample t-Test on Rate of Operating Margin Profit}

The second outcome variable is the rate of operating margin profit. To check whether there is a significant mean difference between control and treated groups in this regard, the two-sample t-test results in manufacturing firms that are involved in credit accession perform better than the non-treated firms. This variation is statistically significant at 5 percent level of significance and recognizing the importance of financial service to the performance of manufacturing firms.

Table 3. Two-sample T-test on outcome variables before matching

\begin{tabular}{lrcccc}
\hline \multicolumn{1}{c}{ Group } & Obs. & Mean & SE & SD & T-Value \\
\hline Controlled & 66 & 1.401434 & 0.0926517 & 0.7527056 & \\
Treated & 42 & 1.704414 & 0.1051044 & 0.6811544 & \\
Combined & 108 & 1.519259 & 0.0709707 & 0.7375491 & \\
\hline \multicolumn{1}{c}{ difference } & & -0.30298 & 0.1432756 & & $\mathrm{t}=-2.1147$ \\
\hline
\end{tabular}

Note: Obs. $=$ Observation, $\mathrm{SE}=$ Standard Error; $\mathrm{SD}=$ Standard Division

\subsection{Econometric Estimation Results}

\subsubsection{Estimating a Model of Program Participant}

The Probit model was used to estimate the propensity score to match the participant with non-participant firms. Credit access is the treatment variable and it takes the value 1 if the treated firms and 0 otherwise. For estimation PSM the study considered different observable characteristics of participants as explained in the covariate.

Table 4. Probit result of participation in financial scheme

\begin{tabular}{llll}
\hline \multicolumn{1}{c}{ Covariant } & \multicolumn{1}{c}{ Coef. } & \multicolumn{1}{c}{ SE } & \multicolumn{1}{c}{$\mathrm{Z}$} \\
\hline Experience & 0.0146309 & 0.0073712 & 1.98 (significant at 5\% sig. level) \\
Employment number & $1.83 \mathrm{E}-04$ & $1.10 \mathrm{E}-03$ & 0.17 \\
Capital & $6.01 \mathrm{E}-09$ & $4.81 \mathrm{E}-09$ & 1.25 \\
Total Expense & $3.3 \mathrm{E}-10$ & $1.91 \mathrm{E}-10$ & 1.73 (significant at 10\% sig. level) \\
Net asset & $-1.07 \mathrm{E}-09$ & $8.01 \mathrm{E}-10$ & -1.34 \\
Constant term & -0.5014529 & 0.2030162 & -2.47 (significant at 1\% sig. level) \\
\hline observation & 107 & & \\
LR chi2(4) & 9.72 & & \\
Prob>chi2 & 0.0454 & & \\
Log-likelihood & -66.813839 & & \\
Pseudo R2 & 0.0678 & & \\
Note: Coef. $=$ Coefficient, SE=Standard Error; Z=Z score Value
\end{tabular}


The model result indicates that year of experience is statistically significant and positively influences the performance of manufacturing firms that can access financial service. It enhances the probability of accessing financial services. In the same manner, the total expense also significantly and positively affecting firms the probability of accessing financial services. In short, the higher expense and longer year of experience, the higher probability of accessing financial services. Both of them are the deriving forces of accessing financial services. However, the number of employees, capital of the firms, and the net asset of the manufacturing firms is statistically insignificant, meaning that they are not as important to increase the probability of accessing financial services in the sampled manufacturing firms.

\subsubsection{Distribution of Propensity Score Matching}

When we see the results of the "psmatch2" estimation, it provides two results. The first one is the "unmatched" results, it shows the difference before matching is taking place. The second result shows the average treatment effect for the treated (ATT), which is the operating margin profit calculated after matching. The result tells that firms that access financial services have 0.36 more profit than firms that do not get financial services. Both results are statistically significant at a 1 percent level of significance as indicated in table 5 .

Table 5. ATT within the common support region

\begin{tabular}{ccccccc}
\hline Variable & Sample & Treated & Controls & Difference & SE & t-statistic \\
\hline \multirow{2}{*}{ Log of Operating Margin } & Unmatched & 1.70441384 & 1.34564331 & 0.358770526 & 0.12595 & 2.85 \\
& ATT & 1.70441384 & 1.3382864 & 0.366127441 & 0.17652 & 2.07 \\
\hline \multirow{2}{*}{ RANERENEASS } & Unmatched & 0.81114286 & 0.435076923 & 0.376065934 & 0.13925 & 2.7 \\
& ATT & 0.81114286 & 0.442785714 & 0.368357143 & 0.17779 & 2.07 \\
\hline
\end{tabular}

Note: $\mathrm{SE}=$ Standard Error; $\mathrm{Z}=\mathrm{Z}$ score Value

To trust the ATT result, it needs to check the balancing by using "pstest", which helps to know how much the bias was eliminated by matching. Table 6 provides the result, in which the mean bias is 4.0 , which shows the matching was good.

Table 6. PSTEST estimation result

\begin{tabular}{|c|c|c|c|c|c|c|c|c|}
\hline \multirow{2}{*}{ Variable } & \multirow{2}{*}{ Unmatched Matched } & \multicolumn{2}{|c|}{ Mean } & \multirow[t]{2}{*}{$\%$ bias } & \multirow{2}{*}{$\begin{array}{l}\text { \%reduct } \\
\text { /bias) }\end{array}$} & \multicolumn{2}{|c|}{ t-test } & \multirow{2}{*}{$\begin{array}{l}\mathrm{V}(\mathrm{T}) / \\
\mathrm{V}(\mathrm{C})\end{array}$} \\
\hline & & Treated & Control & & & $\mathrm{t}$ & $\mathrm{p}>/ \mathrm{t} /$ & \\
\hline \multirow[t]{2}{*}{ Expe } & $\mathrm{U}$ & 17.833 & 11.708 & 34.1 & & 1.77 & 0.079 & 1.71 \\
\hline & M & 17.833 & 17.167 & 3.7 & 89.1 & 0.15 & 0.884 & 0.88 \\
\hline \multirow[t]{2}{*}{ CAP } & $\mathrm{U}$ & $2.00 \mathrm{E}+07$ & $7.10 \mathrm{E}+06$ & 26.1 & & 1.46 & 0.148 & $10.55^{*}$ \\
\hline & M & $2.00 \mathrm{E}+07$ & $2.00 \mathrm{E}+07$ & -1.3 & 94.9 & -0.06 & 0.956 & $3.22 *$ \\
\hline \multirow[t]{2}{*}{ EmpNo } & $\mathrm{U}$ & 86.048 & 70.046 & 4.8 & & 0.25 & 0.803 & $1.91 *$ \\
\hline & M & 86.048 & 83.881 & 1.7 & 63.9 & 0.08 & 0.938 & 1.73 \\
\hline \multirow[t]{2}{*}{ TOEXP } & $\mathrm{U}$ & $7.20 \mathrm{E}+08$ & $2.50 \mathrm{E}+08$ & 26.8 & & 1.43 & 0.154 & $2.9^{*}$ \\
\hline & M & $7.20 \mathrm{E}+08$ & $5.30 \mathrm{E}+08$ & 10.6 & 60.4 & 0.42 & 0.673 & 1.3 \\
\hline \multirow[t]{2}{*}{ NETASS } & $\mathrm{U}$ & $2.40 \mathrm{E}+08$ & $1.80 \mathrm{E}+08$ & 14.8 & & 0.78 & 0.438 & $2.19 *$ \\
\hline & M & $2.40 \mathrm{E}+08$ & $2.30 \mathrm{E}+08$ & 2.4 & 83.8 & 0.1 & 0.921 & 1.28 \\
\hline \multicolumn{9}{|c|}{ *If variance ratio outside $(0.54 ; 1.86)$ and $(0.54 ; 1.86)$ for $\mathrm{M}$} \\
\hline Sample & Ps R2 & LR Chi2 & $\mathrm{p}>\mathrm{chi} 2$ & Mean bias & $\mathrm{B}$ & $\mathrm{R}$ & $\%$ Var & \\
\hline Unmatched & 0.068 & 9.72 & 0.045 & 21.3 & $59.1 *$ & $2.48^{*}$ & 80 & \\
\hline Matched & 0.01 & 1.17 & 0.884 & 4 & 23.4 & 0.77 & 20 & \\
\hline
\end{tabular}

Source: STATA Output 


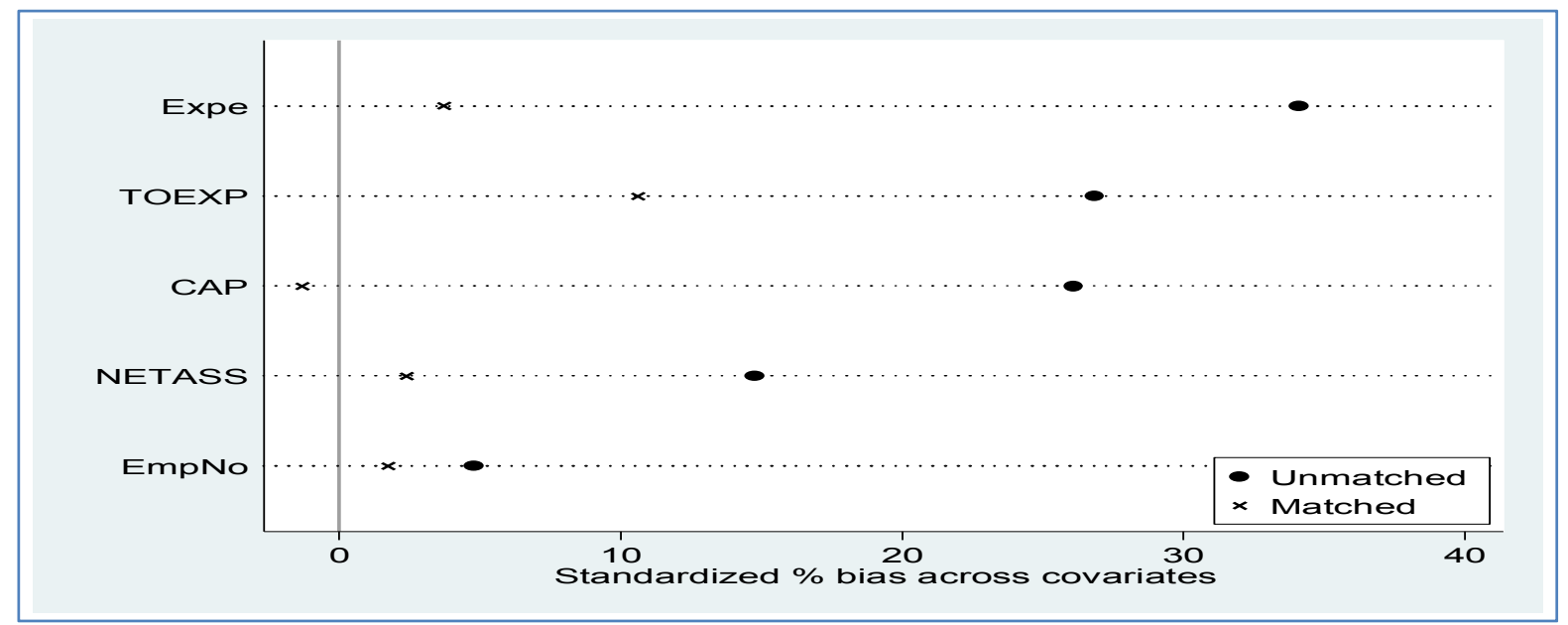

Figure 1. Comparison of density estimation

Source: STATA Output

Figure 1 shows the comparison of density estimation of both treated and untreated groups before matching and after matching was done. On the other hand, Figure 2 presents the histogram of propensity scores to check up if there is enough overlap between treated and control groups. As the graph shows, there is enough overlap or common support between the two groups.

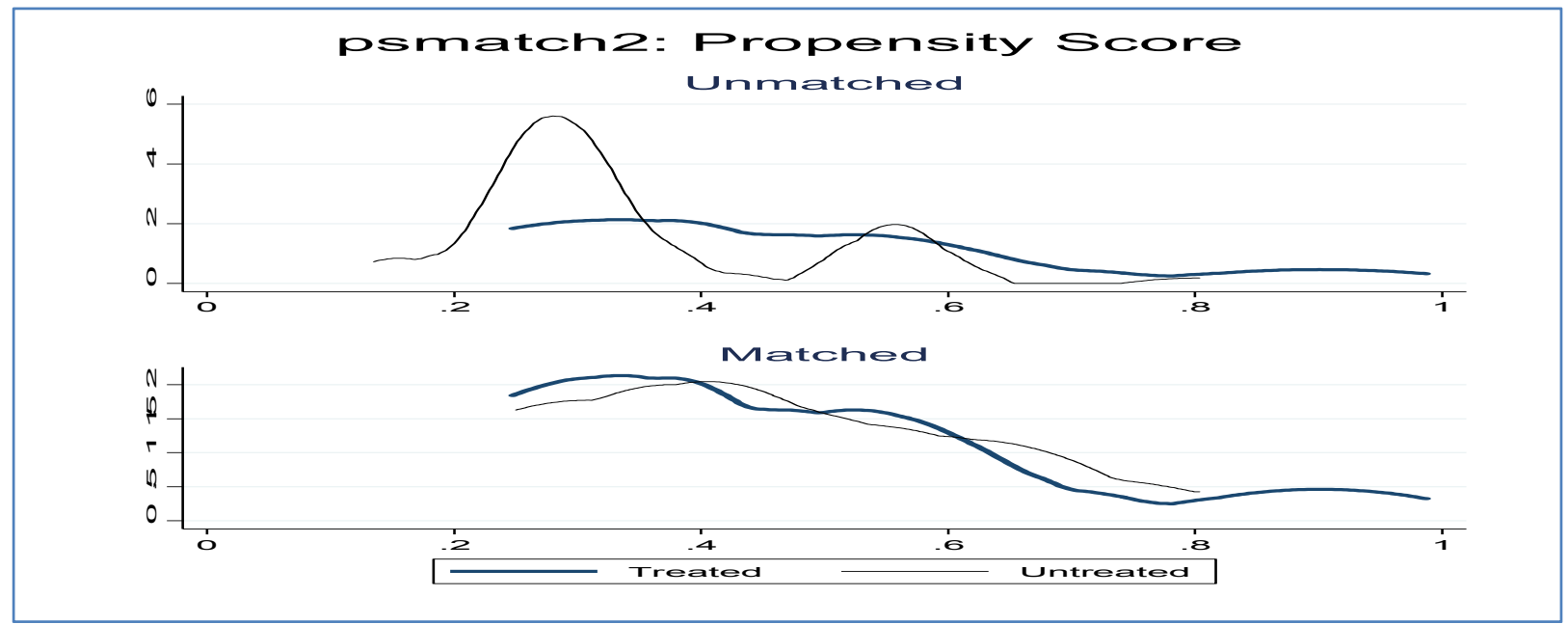

Figure 2. PSTEST graph of samples, both matched and unmatched

Source: STATA Output

\subsubsection{Defining the region of common support and balancing test}

After the estimated propensity score, the next task is to impose a common support condition on the propensity score distributions of firms with and without the financial accession program. The conditional independence and common support assumption of PSM were checked. The optimal number of blocks is five that ensures the mean propensity score is not different for the treated and control households in each block. The average probability to participate in the access to finance program for all respondent were 39 percent. Testing the balancing propensity score is satisfactory.

As to shows that table 7, all the control groups of firms are including on support while none of the firms are off support from the total treated observations. All 108 Firms (100\%) are on support for both outcome variables. This implies that all the off-support observation discarded from both untreated and treated groups. For the decision of on and off, support observation is based on the summarized PS. To check the region of common support we observe if there is enough overlap between the treated group and the control group to make reasonable compassion. From 
the estimated propensity score value, we can see that the length of the common support region is [.1801, .9774]. An observation that is less than the minimum common support value (.1801) is off support values and discarded from the region. As the same thing which is greater than the maximum common support value (.9774) are discarded in the same way. The two groups are only falling into a predefined common support region of the PS of the treated unit.

Table 7. Common support region

\begin{tabular}{ccccccc}
\hline & \multicolumn{3}{c}{ OPERMARGIN } & RANERENEASS \\
\cline { 2 - 7 } & Off & On & Total & Off & On & Total \\
\hline Untreated & 0 & 65 & 65 & 0 & 65 & 65 \\
Treated & 0 & 43 & 43 & 0 & 43 & 43 \\
\hline
\end{tabular}

Source: Own Survey, 2018

As per figure 3, the differentiation regional common support indicated by a different color. The treated case of red on top and the control case of blue on the bottom. There is sufficient overlap in the characteristic of the treated and untreated units. However, there is only one-off support out of the total population.

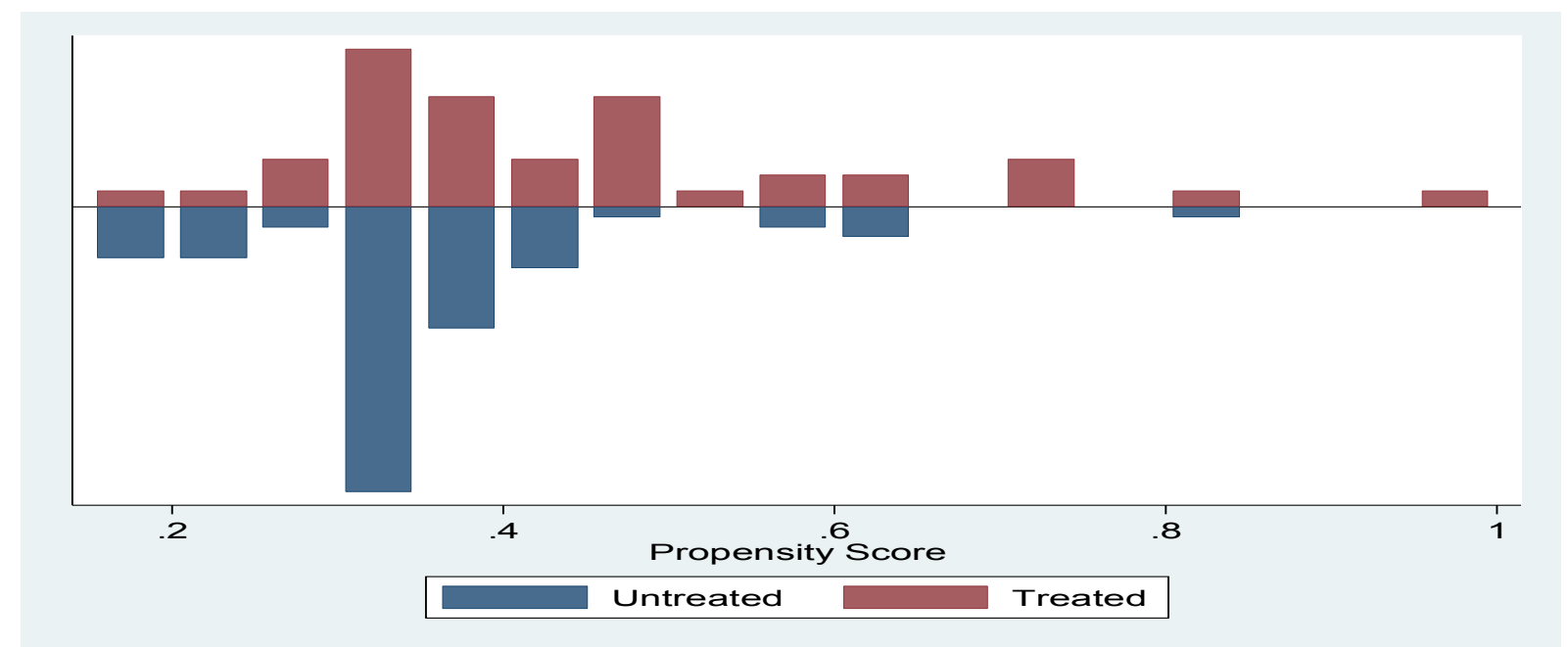

Source: STATA Output

In the case of treatment firms, most of them are found in the middle and partly found on the right side of the distribution. On the other hand, most of the control firms are found in the middle and partly found in the left side of the distribution.

\subsubsection{Matching Participant and Non-Participant Firms}

As stated, before the study employed three main tasks that should be accomplished by matching the treated and control group. First, propensity score value to predict for all manufacturing firms' participants in the program and outside the program. Second, the common support condition should be improved on the propensity score distribution of the treated and control group. Third, sensitivity analyzed employed to check the strength of the estimation of whether unobserved bias affected the estimation ATT or not. The different matching estimator was used to match the treated and control group in the common support region. As per Dehejia and Wahba (2002), the final choice of a matching estimate was guided by different criteria such as the balancing test is equally mean, a low pseudo- $\mathrm{R}^{2}$, and the large sample size is preferred. Accordingly, Caliendo and Kopeining (2008), Kernel matching using a weighted average of all control groups to construct the counterfactual outcome and it's lower variance which is achieved because of more information used, in this method every treated group matched with a control group with a weighted average. 


\subsubsection{ATT Estimation of Finance Using the Four Matching Methods}

To estimate the average treatment effect of the intervention (finance) in the treatment group used different matching algorithms. This includes Nearest-neighbor matching, Caliper or radius matching, Kernel matching, and stratification matching (Khandker et al, 2010).

Table 8 reveals the results of the average treatment effects of access to finance on outcome variables by using different PSM algorithms. It indicates the access to finance has a significant impact on operating margin profit, Hence, the firms that are involved in financial accession have higher average operating margin profit when compared with the untreated firms and the results are statistically significant at 1 percent level of significance. In net return on net asset, the treated groups have $0.36,0.39,0.53$, and 0.4 greater net return on a net asset than nontreated groups by using NNM, KM, SM, and RM, respectively and the results are statistically significant at 1 percent significant level.

Table 8. Average treatment effect on outcome variables by using different PSM algorithms

\begin{tabular}{clccc}
\hline \multicolumn{1}{c}{ Outcome } & \multicolumn{1}{c}{ Matching Method } & ATT & Std. Err. & t-value \\
\hline \multirow{2}{*}{ LOGOPERMARGIN } & Nearest-neighbor matching (NNM) & 0.366 & 0.177 & $2.074^{* *}$ \\
& Kernel Matching (KM) & 0.409 & 0.133 & $3.072^{* * *}$ \\
& Caliper or radius matching (RM) & 0.461 & 0.201 & $2.298^{* *}$ \\
& Stratification or Interval matching (SM) & 0.428 & 0.14 & $3.067^{* * *}$ \\
\hline \multirow{2}{*}{ RANERENEASS } & Nearest-neighbor matching & 0.368 & 0.178 & $2.072^{* *}$ \\
& Kernel Matching & 0.396 & 0.175 & $2.264^{* *}$ \\
& Caliper or radius matching & 0.53 & 0.325 & 1.628 \\
& Stratification or Interval matching & 0.408 & 0.171 & $2.384^{* *}$ \\
\hline
\end{tabular}

$*, * *, * * *$ statistically significant at 10,5 , and 1 percent significant level, respectively.

Source: STATA Output

\subsubsection{Checking Robustness of Average Treatment Effect}

There are several ways to check the robustness of the findings. One approach is to estimate the propensity score equation. Another way to check the robustness of the average treatment effect is to apply direct nearest-neighbor matching instead of estimating the propensity score equation. If both methods give similar results, then the findings are assumed to be more reliable (Khandker et al, 2010).

NNM estimator was used by their consideration cycle have advantageous because they can be used as a way of measuring the robustness of the impact result (Becker \& Ichio, 2002). Comparing different matching methods results is one approach to check the robustness of the average treatment effect. At least, since the findings of the already applied above two matching methods, estimation results are quite similar the paper concludes that the consistency and robustness of PSM analysis.

Table 9. NNMATCH result for operating marring profit

Source: STATA Output

\begin{tabular}{ccccccc}
\hline OPERMARGIN & Coef. & Std. Err. & $\mathrm{z}$ & $\mathrm{P}>\mathrm{z}$ & [95\% Conf. Interval] \\
\hline Fina & 2.619579 & 0.930038 & 2.82 & 0.005 & 0.7967378 & 4.442421 \\
\hline
\end{tabular}

According to Tables 8 and 9, the nnmatch results are consistent with the results provided by different matching methods. The " $z$ " values of both outcome variables are highly significant, having P-value $<0.01$. 
Table 10. NNMATCH result for net return on net asset

\begin{tabular}{lllllll}
\hline OPERMARGIN & Coef. & Std. Err. & $\mathrm{z}$ & $\mathrm{P}>\mathrm{z}$ & \multicolumn{2}{c}{ [95\% Conf. Interval] } \\
\hline Fina & 0.303271 & 0.169559 & 1.79 & 0.074 & -0.0290591 & 0.635601 \\
\hline
\end{tabular}

Source: STATA Output

\subsubsection{Testing Matching Quality or Balance of Propensity Score and Covariant}

The purpose of matching is to balance the treatment and control group on the observation characteristic (Bryson et al, 2002). As stated earlier the main purpose of PS estimation are not to obtain predictions of a selection of treatment rather balance the distribution of relevant variables. By considering a different test method checking the balance such as reduction of mean, standard biases between the matched and unmatched group, using t-test and chi-square are commonly used to balance test to check the quality of means between the treated and control group.

Balancing Test for Propensity Score and Covariates

As we see on the table, the t-value of all covariates is statistically insignificant this indicates that after matching the difference between the mean of the treated and control firms gets minimized. Therefore, we can justify that the matching quality or balancing with PS for all covariates has been satisfied by singing a t-test. Pseudo R2 and Chisquare tests also computed and presented in table 11.

Table 11. Propensity score and covariant balance

\begin{tabular}{lrccccccc}
\hline \multirow{2}{*}{ Variable } & Unmatched & \multicolumn{2}{c}{ Mean } & \multicolumn{4}{c}{ T-Test } \\
\cline { 2 - 10 } & Matched & Treated & Control & \%bias & \% reduction bias & t & p>t & V(T)/VC \\
\hline \multirow{2}{*}{ Years } & Unmatched & 17.833 & 11.708 & 34.1 & & 1.77 & 0.079 & 1.71 \\
& Matched & 17.833 & 17.167 & 3.7 & 89.1 & 0.15 & 0.884 & 0.88 \\
\multirow{2}{*}{ Emp } & Unmatched & 86.048 & 80.046 & 4.8 & & 0.25 & 0.803 & $1.91^{*}$ \\
& Matched & 86.048 & 83.881 & 1.7 & 63.9 & 0.08 & 0.938 & 1.73 \\
\multirow{2}{*}{ Cap } & Unmatched & $2.00 \mathrm{E}+07$ & $7.10 \mathrm{E}+06$ & 26.1 & & 1.46 & 0.148 & $10.55^{*}$ \\
& Matched & $2.00 \mathrm{E}+07$ & $2.00 \mathrm{E}+07$ & -1.3 & 94.9 & -0.06 & 0.956 & $3.22^{*}$ \\
& Unmatched & $7.20 \mathrm{E}+08$ & $2.50 \mathrm{E}+08$ & 26.8 & & 1.43 & 0.154 & $2.90^{*}$ \\
\multirow{2}{*}{ NETASS } & Matched & $7.20 \mathrm{E}+08$ & $5.30 \mathrm{E}+08$ & 10.6 & 60.4 & 0.42 & 0.673 & 1.3 \\
& Unmatched & $2.40 \mathrm{E}+08$ & $1.80 \mathrm{E}+08$ & 14.8 & & 0.78 & 0.438 & $2.19^{*}$ \\
& Matched & $2.40 \mathrm{E}+08$ & $2.30 \mathrm{E}+08$ & 2.4 & 83.8 & 0.1 & 0.921 & 1.28 \\
\hline
\end{tabular}

Source: STATA Output

\subsubsection{Test for Joint Significance of Variables}

The significant result that likelihood ratio (LR) tests and the low pseudo-R2 supports the hypothesis that both groups have the same distribution in covariant after matching. This result shows the matching procedure able to balance the character of the treated and control group. Therefore, as per the table 12 below the mean bias show 4.0 , this indicates that there is an insignificant mean difference between two groups, the standardized mean bias before and after matching, should be less than $5 \%$.

Table 12. Chi-square test for joint significance

\begin{tabular}{cccccccc}
\hline Ps R2 & LR chi2 & p>chi2 & Mean Bias & Med Bias & B & R & \% Var \\
\hline 0.01 & 1.17 & 0.884 & 4 & 2.4 & 23.4 & 0.77 & 20 \\
\hline
\end{tabular}

Source: STATA Output 


\subsubsection{Sensitivity Analysis}

As per Hujer et al. (2004), sensitivity analysis for insignificant effect is not meaningful. Sensitivity analysis provides a method to assess how robust findings are hidden bias assume, all relevant covariance is employed in the treatment assignment. Sensitivity analysis helps also to check the estimated results based on matching are vigorous to the possible presence of unobserved confounders (Keele, 2010). In sensitivity analysis before matching the sample firms assigned to the unknown probability that, the treatment or control groups are independent. In the sample randomize experiment everyone has the same chance to be benefited from the intervention so, $r=1$. If $r=$ 3 in an observational study may be one subject triple as likely to receive the treatment because of unobserved pretreatment difference. The corresponding value of the different sensitivity parameter and each outcome variable is the upper bound $p$-value of Wilcoxon's signed-rank test, if the bias of magnitude $r=2$, it should that have the difference is significant 0.05 level (Rosenbaum, 1983).

As per the result of the operating margin profit outcome and rate of the net return on net asset, respectively, the upper bound on the value $r=1.65$ of the different sensitivity parameters is significant $(p<0.05)$. Therefore, the sensitivity analysis results tell us after matching the treatment and control group as the same covariant may differ from their likelihoods of receiving the treatment by a sensitivity parameter up to $r=2$. The result of sensitivity analysis to check the hidden bias due to unobservable selection shows that all estimated ATTs for all significant outcome variables are insensitive which indicates its robustness.

\section{Conclusion and Policy Implications}

This study examined the impact of access to finance on the performance of manufacturing in Addis Ababa, Ethiopia. Cross-sectional data were gathered from a total of 108 sample Manufacturing firms from Treated and Control groups, which are respectively 42 and 66 firms from each group. Data were gathered from different large and medium manufacturing firms in Ethiopia. Propensity Score Matching (PSM) method was employed to evaluate the impact of access to finance.

The PSM model gives attention to the average treatment effect on the participant (ATT). This is different from the mean value of within and without the intervention, matching was done to compute the average treatment on the treated. The study recognized that the intervention has a positive impact on the operating margin profit and the rate of the net return on the net asset comparing to manufacturing firms without accessing finance. The operating margin profit for firms with credit access is 0.3 percent more than non-participant firms and it is also statistically significant at the 1percnet level. The upper bound on the value $r=1.65$ of the different sensitivity parameters is significant $(p<0.05)$. The result of sensitivity analysis to check the hidden bias due to unobservable selection shows that all estimated ATTs for all significant outcome variables are insensitive which indicates its robustness.

Therefore, the study suggested and forward the following policy implications: Limited access to finance to fund manufacturing projects are the main problems of the manufacturing firms in Ethiopia. Thus, the government should alleviate this problem by coordinately working with financial service providers to make available funds for new investment in the manufacturing sector in addition to giving due attention to reserve foreign currently that useful for importing raw materials and capital goods. The financial institutions should get involved to increase the accessibility of finance products and eliminate the challenge of getting credit by easing legal and administrative processes. Collateral requested by banks must be reasonable regarding the financed project. Other factors like informal payment or bribe should be eliminated and the document requirement should be easily understandable. The finance institution office should give due attention to the manufacturing firms to give more credit to the nonparticipant firms as financial support positively influence the profitability of the manufacturing firms.

Finally, the study has some limitations and recommended further areas of research. Enterprise survey by itself is complex by nature to get reliable data from firms. The study used data by extracting real information from the sources and promoters with all possible options. If this were done countrywide, it would be very challenging to conduct such a survey without the intervention of the government. First of all, it should convince firms and comprehensively conduct a survey, meeting reliability criteria, and without missing relevant information. On top of this, the study focused on the impact of access to finance on the profitability of manufacturing firms by considering the paid-up capital of the firm, number of employees, experience of the firms, total expense, and total asset. However, other variables can directly affect the profitability of the firms, and the paper recommended further studies on the nexus between manufacturing projects and finance sector at the national level that helps policymakers to maximize the benefit of financial accessions to manufacturing firms.

\section{References}

Andrea, P., \& Christoph, R. W. (2009). Evaluating the effects of farm programmes: results from propensity score 
matching. European Review of Agricultural Economics, 36(1), 79-101. Retrieved from http://hdl.handle.net/10.1093/erae/jbp001

Anthony, K. (2012). Access to Credit and Growth of Small and Medium Scale Enterprises in the Ho Municipality of Ghana. British Journal of Economics, Finance, and Management Sciences.

Arcand, J.-L., Berkes, E., \& Panizza, U. (2015). Too much finance? Journal of Economic Growth, 20, 105.

Arturo, G., \& Schiantarelli, F. (2002). Credit Constraints in Latin America: An Overview of the Micro Evidence. IDB Working Paper No. 395. https://dx.doi.org/10.2139/ssrn.1807609

Beck, T., Asli, D.-K., \& Ross, L. (2005). SMEs, Growth, And Poverty: Cross-Country Evidence. Journal of Economic Growth, 10(3), 199-229.

Becker, \& Ichio. (2002). Estimation of average treatment effects based on propensity scores. Retrieved from https://EconPapers.repec.org/RePEc:tsj:stataj:v:2:y:2002:i:4:p:358-377

Bryson, A., Richard, D., \& Susan. (2002). The Use Of Propensity Score Matching In The Evaluation Of Active Labour Market Policies, Policy Studies Institute and National Centre for Social Research, Working Paper 4.

Caliendo, \& Kopeining. (2008). Some Practical Guidance for the Implementation of Propensity Score Matching. https://doi.org/10.1111/j.1467-6419.2007.00527.

CSA. (2016). Report on Large and medium scale manufacturing and electricity industries survey. Addis Ababa.

De la Torre, A., Feyen, E., \& Ize, A. (2011). Financial development: structure and dynamics. Policy Research Working Paper Series 5854, The World Bank.

Dehejia and Wahba. (2002). Propensity Score-Matching Methods For Nonexperimental Causal Studies. The Review of Economics and Statistics, 84(1). Retrieved from http://www.mitpressjournals.org/doi/pdf/10.1162/003465302317331982

EBR. (2017). Ethiopian Business Review. Review, Ethiopian Business.

Gabriel, K., \& Kung, U. (2011). Factors influencing SMEs access to finance: A case study of Westland Division, Kenya, MPRA Paper 66633, University Library of Munich, Germany, revised 2014.

Goldsmith. (1969). Financial Structure and Development. Yale University Press.

Greenwood, \& Jovanovic. (1990). Financial Development, Growth, and the Distribution of Income. Journal of Political Economy, 98(5), 1076-1107. Retrieved from http://www.jstor.org/stable/2937625

Habibullah, \& Eng. (2006). Does Financial Development Causes Economics Growth? A Panel Data. https://doi.org/10.1080/13547860600923585

Heckman, J. J. (1997). Matching as an Econometric Evaluation. The Review of Economic Studies, 64(4), 605-654. https://doi.org/10.2307/2971733

Hujer, R., Caliendo, M., \& Thomsen, S. (2004). New Evidence on the Effects of Job Creation Schemes in Germany - A Matching Approach with Threefold Heterogeneity. Research in Economics, 58(4), 257-302.

Keele. (2010). An overview of rebounds: An R package for Rosenbaum bounds sensitivity analysis with matched data.

Kopeining, S., \& Marco, C. (2008). Some Practical Guidance for the Implementation of Propensity Score Matching. Journal of Economic Surveys, 22(1), 31-72. https://doi.org/10.1111/j.1467-6419.2007.00527

La Porta, R., Florencio, L.-de-S., Andrei, S., \& Robert, W. V. (1998). Law and Finance. Journal of Political Economy, 106(6), 1113-1155. https://doi.org/10.1086/250042

Lucas, R. (1988). On The Mechanics of Economic Development. Journal of Monetary Economics, 22, 3-42. NorthHolland, University of Chicago, Chicago, 1L 60637, USA.

MaKinnon. (1973). Money and Capital in Economic Development, Brooking Institutes, Washington, DC. Pp. 177. index. World Development, 2(3), 87-88.

MoEFC. (2016). Raw data on the national account of Ethiopia. Addis Ababa: Ministry of Economy \& Financial Cooperation.

Patrick. (1966). Financial Development and Economic Growth in Under Developed Countries. The University of Chicago Press Journal. Retrieved from https://www.jstor.org/stable/1152568?seq=1

Plane, P., Marie-Ange, V., \& Tidiane, K. (2011). Firm Productivity and Investment Climate in Developing 
Countries: How Does the Middle East and North Africa Manufacturing Perform?

Pufahl, A., \& Weiss, C. (2009). Evaluating the effects of farm programs: results from propensity score matching.

Rosenbaum, P., \& Rubin, D. (1983). The central role of the Propensity Score in Observational study for causal Effects. Biometrika, 70(1), 41-55. https://doi.org/10.1093/biomet/70.1.41

Rousseau, P. L., \& Wachtel, P. (2011). What Is Happening To The Impact Of Financial Deepening On Economic Growth? Economic Inquiry, 49(1), 276-288.

Saad. (2006). Pro-Poor Monetary Policy towards a macroeconomic Framework for Growth and Poverty.

Shahidur, R., Khandker, S., Koolwal, G., \& Samad, H. (2009). Handbook on Impact Evaluation Quantitative Methods and Practices. Retrieved

from htttp://documents.worldbank.org/curated/en/650951468335456749/pdf

Shaw. (1973). Financial Deepening in Economic Development, Oxford University Press, New York. American Journal of Agricultural Economics, 56(3), 670. https://doi.org/10.2307/1238641

\section{Copyrights}

Copyright for this article is retained by the author(s), with first publication rights granted to the journal.

This is an open-access article distributed under the terms and conditions of the Creative Commons Attribution license (http://creativecommons.org/licenses/by/4.0/). 